\title{
A Retrospective study on patients with intestinal fistula and management in Damascus hospital between 2015-2022
}

Khalil Alkurdi

Syrian private university

Ramez Aljalloud

Syrian private university

Saeed A.Kadri ( $\sim$ saeedkadri1997@gmai.com )

Syrian private university

Ezat Albakri

Syrian private university

Mohamad Jeha

Syrian private university

AbdAlkarim Alomar

Syrian private university

M.A.Kubtan

Syrian private university

\section{Research Article}

Keywords: Intestinal fistula, perianal, relapsing, Crohn's disease

Posted Date: February 28th, 2022

DOI: https://doi.org/10.21203/rs.3.rs-1397141/v1

License: (c) (i) This work is licensed under a Creative Commons Attribution 4.0 International License. Read Full License 


\section{Abstract \\ Background}

Intestinal fistula is an irregular opening that enables the contents to flow out. Surgical procedures, diverticular illness, inflammatory bowel disease, cancer, radiation, and injury from trauma or foreign bodies are all common causes of intestinal fistulas.

\section{Aims}

The goal is to see if smoking is a risk factor for relapsing in patients with intestinal fistula, as well as to learn more about the most common cause of perianal abscess or fistula, which will provide us with more information about risk factors that can be avoided and early diagnostic investigations that will help us detect the disease early and limit its progression.

\section{Methods}

Patients who presented to Damascus Hospital with complaints of intestinal fistula symptoms and were diagnosed and treated in the general surgery and gastroenterology divisions between 2015 and 2022 and met admission requirements were included in the retrospective analysis.

\section{Results}

Out of 104 cases of fistula, the average age was 34.96 , with a male-to-female ratio of $67-33 \%$. The overall percentage of smokers in the sample is $59 \%$, and the pathological history includes 43 cases of Crohn's Disease and eight cases of colon cancer. A history of surgery was found in $63 \%$ of the participants. Surgical treatment was used on $53 \%$ of the fistulas, whereas conservative treatment was used on $47 \%$. The proportion of patients who relapsed was $77 \%$ in smokers and $31 \%$ in nonsmokers, with a statistically significant difference. In addition, when we looked at the occurrence of perianal abscess or fistula in patients with Crohn's disease, we discovered that 96 percent of patients with perianal fistula have Crohn's disease, indicating a statistically significant relationship between these two conditions.

\section{Conclusion}

Smoking and Crohn's disease have a statistically significant relationship with relapsing and the development of a perianal abscess or fistula.

\section{Introduction}


A fistula is a connection between two epithelial surfaces that is aberrant. An intestinal fistula is a connection between the intestine and another organ or surface. ${ }^{4}$ Fistulas of the gastrointestinal tract are frequently life-threatening complications with significant rates of morbidity and mortality. They allow aberrant gastrointestinal contents, gastric enzymes, water, electrolytes, and nutrients to be diverted from one hollow organ to another or to the skin, resulting in a wide range of pathological effects. ${ }^{2}$

Operative intervention is responsible for $80-90 \%$ of all small-bowel fistulas. ${ }^{6}$ Infection, ischemia, pressure, or distal obstruction can all cause an intestinal anastomosis to break down, resulting in the formation of a postoperative fistula. ${ }^{3}$ Inflammatory processes, cancer, radiation therapy, and infectious diseases account for $10-20 \%$ of all small-bowel fistulas. Crohn's disease accounted for $5-50 \%$ of the 10-20 percent, with cancer responsible for $2-15 \%$, peptic ulcer disease accounting for $3-5 \%$, pancreatitis $3-10 \%$, radiation therapy accounting for $2-5 \%$, and infections accounting for $2-5 \%{ }^{6}$ Symptoms of fistulas which include two segments of the gut vary depending on where the fistula is located and how much bowel is bypassed. As a result, entero-enteric fistulas that bypass just a small segment of the bowel may be asymptomatic and discovered coincidentally after surgery or based on imaging results. An ileo-sigmoid fistula, on the other hand, can result in diarrhea, weight loss, or stomach pain. ${ }^{2}$

The investigation differs depending on the location and symptoms, the history and clinical examination are essential in diagnosing. CT scanning of the abdomen and pelvis is the imaging modality of choice for evaluating potential fistulas. Fistulography and endoscopy are also utilized to locate and measure the fistula's location and size. ${ }^{1}$ Appropriate nutrition, control and maintenance of the fistula drainage site, appropriate infection treatment, and prevention of sepsis are all essential to successfully treat individuals with an intestinal fistula. ${ }^{8}$ Nonoperative management has been demonstrated to cause fistulas to close spontaneously in some cases. If the fistula is iatrogenic, there is no distal blockage, no foreign body, the tract is long, the output is low, and there is no active infection, the fistula is 60 percent or more near to being healed. ${ }^{7}$

The goal of this research is to look at the many types of fistulas that can be induced by various etiologies such as Crohn's disease and operative intervention. Also, to determine the relapse rate in relation to elements that have a negative impact on the fistula. And to understand the various management options based on the fistula's location.

\section{Methods}

104 patients with various types of fistulas who were diagnosed and treated in the general surgery and gastroenterology divisions of Damascus hospital between 2015 and 2022 were studied retrospectively. Patients' demographics, such as gender, age, and smoking status, as well as their medical, surgical, and pharmacotherapeutic histories, as well as their symptoms, were all collected. The location of the fistula and the type of treatment (conservative or surgical), diagnostic methods, and causative agents were all documented. 
Inclusion criteria:

1- Age of patients over 18 years old.

2- The presence of a fistula that does not meet the exclusion criteria.

3- Patients admitted to the general surgery and gastroenterology divisions between 2015-2020

Exclusion criteria:

1- Archiving errors.

2- Misdiagnosed cases of intestinal fistula.

3- Cases have missing data that cannot be studied.

Ethical approval:

Ethical approval was granted from the Institutional Review Board (IRB), Faculty of Medicine, Syrian Private University, Daraa, Syria, and from Damascus Hospital Institutional Review Board (IRB).

Statistical analysis:

Data were analyzed using the Statistical Package for Social Sciences version 25.0 (SPSS Inc., Chicago, IL, United States) and reported as frequencies and percentages (for categorical variables) or means, medians, and standard deviations (SD) (for continuous variables). $\mathrm{P}<0.05$ was considered significant.

\section{Results}

\section{Patients' characteristics:}

There were 70 men (67\%) and 34 women (33\%) among the total of 104 patients. The patients' ages ranged from 18 to 74, with a mean of 34.96 (12.63) years. There were 61 (59\%) patients who smoked, with $57(93 \%)$ men and $4(7 \%)$ women among them. $43(41 \%)$ of the 53 patients with a medical history have Crohn's disease, $4(4 \%)$, have hypertension, $3(3 \%)$, have diabetes mellitus, and $3(3 \%)$, have a peptic ulcer. Seventy-one percent of patients had a prior pharmacotherapeutic history, while the remaining 29 percent did not. Figure 1 depicts the percentage of different types of fistulas recorded in records. The patient's main complaint and diagnostic procedures were categorized based on the location of the fistula, as shown in table 1. Individuals with Crohn's disease have the highest rate of relapse out of all the variables that induce fistula, with 38 patients relapsing out of $43(88 \%)$.

Table (1): The chief complaint and diagnostic techniques based on the fistula's location. 


\begin{tabular}{|c|c|}
\hline Entero-enteric & Number (\%) \\
\hline \multicolumn{2}{|l|}{ Chief complaint } \\
\hline Abdominal pain + fatigue and weakness + weight loss & $22(55)$ \\
\hline Abdominal pain + fatigue and weakness & $15(38)$ \\
\hline Critically ill condition & $3(8)$ \\
\hline \multicolumn{2}{|l|}{ Diagnostic techniques } \\
\hline Endoscopy & $22(55)$ \\
\hline CT scanning & $9(23)$ \\
\hline Ultrasonography & $3(7)$ \\
\hline Fistulography & $6(15)$ \\
\hline \multicolumn{2}{|l|}{ Entero-cutaneous } \\
\hline \multicolumn{2}{|l|}{ Chief complaint } \\
\hline Malodorous excretion + abdominal pain & $32(82)$ \\
\hline Abdominal pain + fatigue and weakness + weight loss & $6(15)$ \\
\hline Abdominal pain + fatigue and weakness & $1(3)$ \\
\hline \multicolumn{2}{|l|}{ Diagnostic techniques } \\
\hline Clinical Examination & $13(33)$ \\
\hline Ultrasonography & $9(23)$ \\
\hline CT scanning & $7(18)$ \\
\hline Endoscopy & $6(15)$ \\
\hline Surgical & $3(8)$ \\
\hline Fistulography & $1(3)$ \\
\hline \multicolumn{2}{|l|}{ Entero-vesical } \\
\hline \multicolumn{2}{|l|}{ Chief complaint } \\
\hline Frothy urine + Fever & $6(86)$ \\
\hline Abdominal pain + fatigue and weakness & $1(14)$ \\
\hline \multicolumn{2}{|l|}{ Diagnostic techniques } \\
\hline Fistulography & $6(86)$ \\
\hline Endoscopy & $1(14)$ \\
\hline
\end{tabular}




\begin{tabular}{|c|c|}
\hline \multicolumn{2}{|l|}{ Entero-vaginal } \\
\hline \multicolumn{2}{|l|}{ Chief complaint } \\
\hline Malodorous Excretion from vagina + Fever & $7(100)$ \\
\hline \multicolumn{2}{|l|}{ Diagnostic techniques } \\
\hline Fistulography & $7(100)$ \\
\hline \multicolumn{2}{|l|}{ Umbilical fistula } \\
\hline \multicolumn{2}{|l|}{ Chief complaint } \\
\hline Malodorous Excretion from Umbilicus & $4(100)$ \\
\hline \multicolumn{2}{|l|}{ Diagnostic techniques } \\
\hline CT scanning & $4(100)$ \\
\hline \multicolumn{2}{|l|}{ Entero-Enteric +Entero-cutaneous } \\
\hline \multicolumn{2}{|l|}{ Chief complaint } \\
\hline Abdominal pain + fatigue and weakness + weight loss & $4(100)$ \\
\hline \multicolumn{2}{|l|}{ Diagnostic techniques } \\
\hline Endoscopy & $4(100)$ \\
\hline \multicolumn{2}{|l|}{ Entero-vesical + Entero-cutaneous } \\
\hline \multicolumn{2}{|l|}{ Chief complaint } \\
\hline Abdominal pain + fatigue and weakness + weight loss & $3(100)$ \\
\hline \multicolumn{2}{|l|}{ Diagnostic techniques } \\
\hline Endoscopy & $3(100)$ \\
\hline
\end{tabular}

\section{Smoking and relapsing:}

Patients with relapsing history were evaluated for their smoking habits, and 47 (77\%) of the 60 patients smoked, while the remaining $13(31 \%)$ did not. Patients who smoked but did not have a relapse history comprise $14(23 \%)$ of the total, while the remaining $30(69 \%)$ have no history of relapse or smoking, as shown in table 2.

The difference between the relapsing and non-relapsing groups was statistically significant with a $p$ value of $\mathbf{0 . 0 0 1 *}$, according to statistical analysis using the chi-square test.

Table (2): depicts the smoking history of relapsing patients. 


\begin{tabular}{|lllll|}
\hline & Relapsing & Not relapsing & Total & P value \\
\cline { 1 - 4 } & Number (\%) & Number (\%) & Number (\%) & \\
\cline { 1 - 4 } Smoking & $47(77)$ & $14(23)$ & $61(100)$ & \multirow{2}{*}{.001* } \\
\cline { 1 - 4 } No smoking & $13(31)$ & $30(69)$ & $43(100)$ & \\
\hline
\end{tabular}

\section{Crohn's disease and perianal fistula:}

A perianal fistula or abscess affects 25 of the 43 people with Crohn's disease, whereas only one patient without Crohn's disease has one, as mentioned in table 3.

According to statistical analysis using the chi-square test, we discovered a positive significant association between the development of perianal abscess or fistula and Crohn's disease, with a $p$ value of $0.001 *$.

Table (3): represent the perianal abscess or fistula among patients with or without Crohn's disease.

\begin{tabular}{|llll|}
\hline \multirow{2}{*}{ Perianal abscess or fistula } & With Crohn's disease & Without Crohn's disease & P value \\
\cline { 2 - 3 } & Number (\%) & Number $(\%)$ & \\
\hline Yes & $25(96)$ & $1(4)$ & 0.001 * \\
\hline No & $18(23)$ & $60(77)$ & \multirow{2}{*}{} \\
\hline
\end{tabular}

\section{Discussion}

A fistula is an irregular connection between two epithelialized surfaces that commonly involves the gut and another hollow organ, such as the bladder, urethra, vagina, or other parts of the gastrointestinal (GI) tract. Patients suffering from this type of improper communication must deal with the repercussions of gut contents leakage as well as the anxiety of not knowing how or if the condition will be rectified.

There was a high statistical relationship between smoking and the frequency of recurrence in our study, with 77 percent of patients suffering from it, and this was consistent with the study of (Lindberg, E., G. Järnerot, and B. Huitfeldt) ${ }^{5}$

And, by examining the occurrence of perianal abscess or fistula in patients with Crohn's disease, we discovered a strong statistical link between Crohn's disease and diagnosing a fistula or abscess, with 25 patients with perianal fistula (96 percent) having Crohn's disease and only one patient with perianal 
fistula not having Crohn's disease, our findings match those of (Safar B, Sands D) ${ }^{9}$, who found a 3.8-80\% incidence of perianal fistula in individuals with Crohn's disease.

\section{Conclusion}

Relapsing and developing perianal fistula show a statistically significant relationship with smoking and Crohn's disease, respectively. When a patient has an intestinal fistula, it's critical to counsel them to quit smoking, and people with Crohn's disease should never be afraid to question their doctors if they have an atypical condition related to their disease.

\section{Declarations}

\section{Acknowledgments:}

We appreciate the cooperation of the Syrian Private University and the Damascus Hospital in the field of medical education and research. We would also like to express our gratitude to Dr. M.A.Kubtan for his assistance and oversight of the work.

\section{Funding:}

This research received no specific grant from SPU or any other funding agency in the public, commercial or non-profit sectors.

\section{Availability of data and materials:}

All data related to this paper's conclusion are available and stored by the authors. All data are available from the corresponding author on a reasonable request.

\section{Ethics approval and consent to participate:}

This study was approved by the Institutional Review Board (IRB) at the Damascus Hospital. All information collected from this study was kept strictly confidential.

\section{Consent for Publication:}

Not applicable.

\section{Competing interests:}

The authors declare that they have no competing interests.

\section{Authors' contributions:}


KA and RA conceptualized the study, wrote the study protocol, performed the statistical analysis, participated in data collection, and did the literature search. S.A.K did the translation of this study, made the design of this paper and did the publishing. M.A.K did a literature search and revision of the draft. All authors read and approved the final draft.

\section{References}

1. David E Stein, MD, Asyia S Ahmad, MD, Burt Cagir, MD, Radha V Menon, MD, Christopher K Chiu, MD, Francisco Talavera, PharmD, Updated: Mar 08, 2018.

2. Falconi M, Pederzoli P. The relevance of gastrointestinal fistulae in clinical practice: a review. Gut. 2001 Dec. 49 Suppl 4: iv2-10. [QxMD MEDLINE Link].

3. Fazio V, Coutsoftides T, Steiger F. Factors influencing the outcome of treatment of small bowel cutaneous fistula. World J Surg 1983;7:481-8.

4. Ioannidis O, Paraskevas G, Kakoutis E, Kotronis A, Papadimitriou N, Chatzopoulos S, Makrantonakis A. Coexistence of multiple omphalomesenteric duct anomalies. J Coll Physicians Surg Pak. 2012 Aug;22(8):524-6. [PubMed] [Ref list].

5. Lindberg, E., G. Järnerot, and B. Huitfeldt. "Smoking in Crohn's disease: effect on localisation and clinical course." Gut 33.6 (1992): 779-782.

6. Neelu Pal, MD, Francisco Talavera, PharmD, PhD, David L Morris, MD, John Geibel, MD, Brian J Daley, MD, Updated: Sep 28, 2021.

7. Panes J, Rimola J. Perianal fistulizing Crohn's disease: pathogenesis, diagnosis and therapy. Nat Rev Gastroenterol Hepatol. 2017 Nov. 14 (11):652-64. [QxMD MEDLINE Link].

8. Rolandelli R, Roslyn JJ. Surgical management and treatment of sepsis associated with gastrointestinal fistulas. Surg Clin North Am. 1996 Oct. 76 (5):1111-22. [QxMD MEDLINE Link].

9. Safar B, Sands D. Perianal Crohn's disease. Clin Colon Rectal Surg. 2007;20(4):282-293. doi:10.1055/s-2007-991027

\section{Figures}




\section{Type of fitulas}

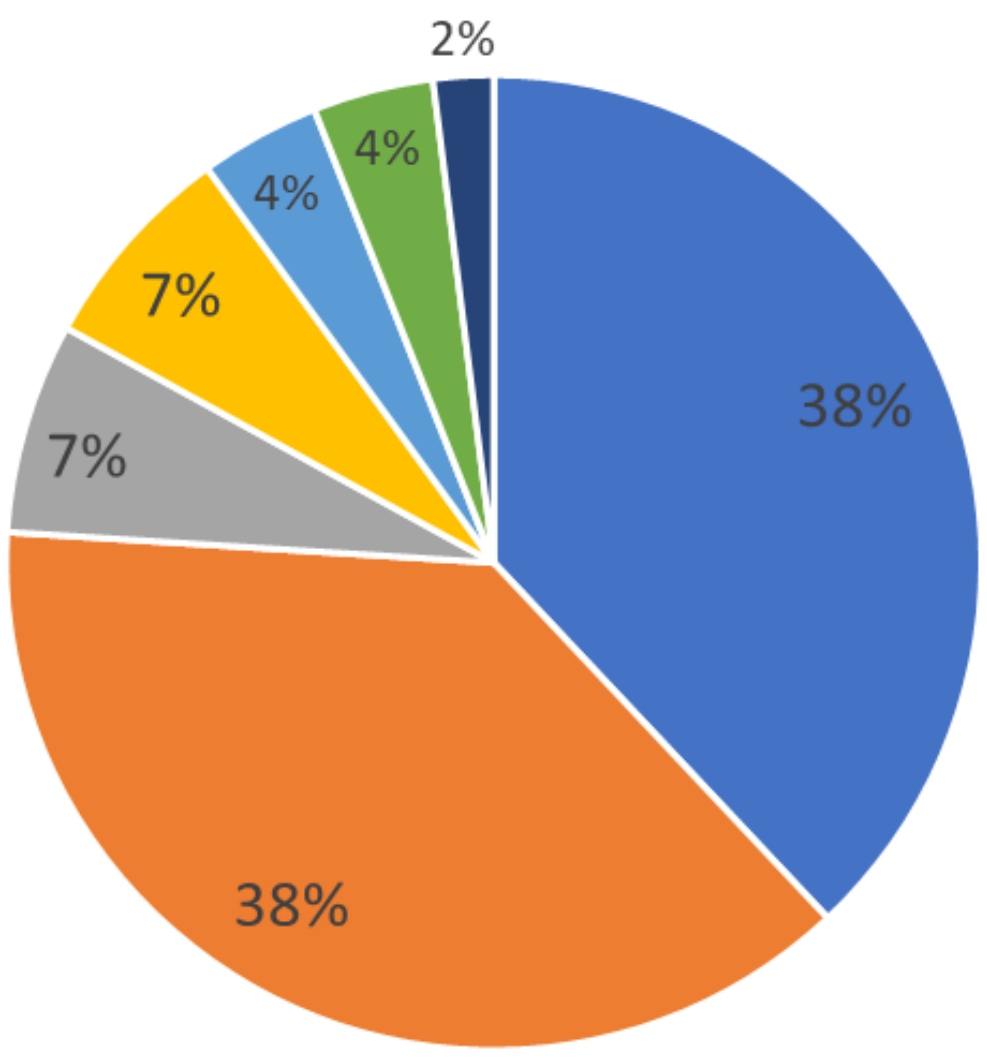

- Enteroenteric

- Enterocutaneous

- Enterovesical

Enterovaginal

- Umbilical fistula

- Enteroenteric+Enter ocutaneous

- Enterovesical+Enter ocutaneous

Figure 1

represent the percentage of different types of fistulas. 